\title{
Drug use and postgraduate students' career prospects: Implications for career counselling intervention strategies
}

\begin{tabular}{|c|c|}
\hline $\begin{array}{l}\text { Authors: } \\
\text { Thabiso Musu } \\
\text { Cornelis J. Roe }\end{array}$ & $\begin{array}{l}\text { ede }^{1} \\
\text { lofse }^{2}\end{array}$ \\
\hline $\begin{array}{l}\text { Affiliations: } \\
{ }^{1} \text { Department } \\
\text { Communicatic } \\
\text { Information S } \\
\text { University of } \\
\text { South Africa }\end{array}$ & $\begin{array}{l}\text { f Media, } \\
\text { n and } \\
\text { udies, } \\
\text { impopo, }\end{array}$ \\
\hline $\begin{array}{l}{ }^{2} \text { Department } \\
\text { and Criminal J } \\
\text { University of } \\
\text { South Africa }\end{array}$ & $\begin{array}{l}\text { f Criminology } \\
\text { ustice, } \\
\text { impopo, }\end{array}$ \\
\hline $\begin{array}{l}\text { Correspondin } \\
\text { Cornelis Roelc } \\
\text { roelofsec@un }\end{array}$ & $\begin{array}{l}\text { author: } \\
\text { fse, } \\
\text { zulu.ac.za }\end{array}$ \\
\hline $\begin{array}{l}\text { Dates: } \\
\text { Received: } 09 \text { । } \\
\text { Accepted: } 31 \\
\text { Published: } 03\end{array}$ & $\begin{array}{l}\text { lov. } 2017 \\
\text { uly } 2018 \\
\text { Dec. } 2018\end{array}$ \\
\hline $\begin{array}{l}\text { How to cite th } \\
\text { Muswede, T. } \\
\text { 2018, 'Drug us } \\
\text { postgraduate } \\
\text { career prospe } \\
\text { Implications f } \\
\text { counselling in } \\
\text { strategies', Th } \\
\text { Transdisciplin } \\
\text { Southern Afric } \\
\text { https://doi.or } \\
\text { td.v14i1.523 }\end{array}$ & $\begin{array}{l}\text { is article: } \\
\text { Roelofse, C.J., } \\
\text { e and } \\
\text { tudents' } \\
\text { ts: } \\
\text { r career } \\
\text { ervention } \\
\text { Journal for } \\
\text { rry Research in } \\
\text { a } 14(1) \text {, a523. } \\
\text { /10.4102/ }\end{array}$ \\
\hline $\begin{array}{l}\text { Copyright: } \\
\text { (c) 2018. The } \\
\text { Licensee: AOS } \\
\text { is licensed un } \\
\text { Creative Comr } \\
\text { Attribution Lic }\end{array}$ & $\begin{array}{l}\text { uthors. } \\
\text { S. This work } \\
\text { ler the } \\
\text { nons } \\
\text { ense. }\end{array}$ \\
\hline Read online: & \\
\hline 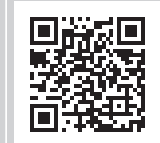 & $\begin{array}{l}\text { Scan this QR } \\
\text { code with your } \\
\text { smart phone or } \\
\text { mobile device } \\
\text { to read online. }\end{array}$ \\
\hline
\end{tabular}

The study investigates the effect of drug use on postgraduate students' career prospects by exploring associated risks of drug use and subsequent implications for career counselling intervention strategies within a university context. Students' awareness of the psychosocial and health risks of drug use, knowledge and use of existing drug intervention services as well as behavioural impediments to their career prospects are assessed. An exploratory design within the qualitative approach was adopted involving in-depth interviews with professional informants and drug users within the postgraduate student cohort. Interpretive phenomenological analysis was applied for the synthesis and formulation of discursive themes. The article notes that denial and lack of coping strategies, improper personal conduct and unresponsive behaviour; poor academic performance and incriminating personal profiles were major potential impediments to postgraduate students' career prospects. It was further noted that the current interventions' continued use of scare tactics and information-based programmes needed to undergo a systematic evaluation. The article calls for more inclusive intervention strategies based on the life skills approach to address poor social coping strategies, mundane decision-making, low self-esteem and weak peer pressure resistance mechanisms to enhance students' sober habits and competitiveness in the job market.

\section{Introduction}

Despite the dearth of reliable systems to facilitate the collection of data relating to substance abuse in South Africa (Kyei \& Ramagoma 2013), substance dependence statistics show that the consumption level of South Africans is twice the global average and second to none in Africa (United Nations 2014). Recent press reports have speculatively presented South African university campuses as unsafe for students owing to the unprecedented culture of substance abuse, particularly that associated with alcohol and drug consumption (Agumba \& Musonda 2014). Seen as a defining feature of the tertiary education lifestyle, students' indulgence in substance abuse has significant potential to derail them from their prime focus of embarking on academic endeavours (Towl 2004). This is contrary to the expected norm that a university should provide a safe, enriching and rewarding educational experience for students to develop their social and intellectual skills. Despite the clear enactment of regulatory mechanisms that outlaw substance abuse in the country, especially illicit drugs, substance abuse among university students remains a major cause of concern (Goreishi \& Shajari 2013). In certain instances, universities have experienced irregular class attendance and subsequent poor academic performance among students who abuse drugs and alcohol (Kyei \& Ramagoma 2013).

The significance of studying the effects of substance abuse, particularly drugs among young people in universities, stems from the substances' potential to limit or obstruct the users' ability to make good choices in life (Kyei \& Ramagoma 2013). This entails engaging in irresponsible activities, including indulging in unprotected casual sex and binge drinking under the influence of intoxicating substances, an experience they often regret afterwards (Matlou 2016). Overall, drug abuse has been attributable to social settings and social influences, which suggests that most students get involved for social reasons than otherwise (Tayob \& Van der Heever 2014). In the university context, this includes special day celebrations such as birthdays, graduation ceremonies and calendar events in the form of fresher's ball and bashes. Thus, authorities have continued to struggle to contain alcohol and drug consumption among students of all levels (Agumba \& Musonda 2014), a spectre that minimises their opportunity to enter the job market and pursue their career aspirations. Because of the debilitating effects of substance abuse, there is a need to explore the risks and implications of such behaviour. Data and findings on substance abuse are 
critical in informing the design and implementation of intervention strategies at any given time.

Despite the dearth of studies that have focused on the effects of substance abuse in colleges or universities in the recent past (Goreishi \& Shajari 2013; Tayob \& Van der Heever 2014), a review of the existing few cases tend to treat the student body (including postgraduates) as a homogeneous group whose encounter with substance abuse is limited to the quantification of user's perceptions, attitudes or prevalencerelated variables. Despite their invaluable contribution to the understanding of the nature of substance abuse, most of these investigations have largely been informed by the general approach, where undergraduate students are the target groups of the inquiry with little regard for postgraduate students as a significant group on their own. This study acknowledges postgraduate students' experiences as people who are familiar with university life and are expected to operate at a level of 'maturity' above that of the undergraduates. This is generally expected to assist them to develop adaptive, forthright and responsible decisionmaking mechanisms to avoid the drug-alcohol scourge. Nonetheless, indications are that drug use is on the increase among students, with the potential to negatively affect their career prospects. Hence, the study aims to qualitatively investigate the effect of drug use on postgraduate students' career prospects in a South African university context. It assesses students' awareness of the psychosocial and health risks associated with drug use, determines students' knowledge and use of existing drug control systems and further explores behavioural impediments of drug use on students' career opportunities.

\section{Prevalence and effect of drug abuse in universities}

The prevalence and effect of drug abuse among young people is an important aspect in understanding potential consequences this behaviour may have on their future career opportunities. Over the years, some surveys have lamented the unprecedented rate of substance abuse in institutions of higher learning, particularly universities (Peltzer \& Ramlagan 2009; Tayob \& Van der Heever 2014). In these studies, scholars have argued that the university in particular is a critical environmental factor that contributes to uncontrolled substance abuse, particularly alcohol and drugs. For most students, staying on campus exposes them to the bad influence of friends whose abuse of illicit substances causes them to abandon their first-year innocence carried over from their respective high schools as a product of parental monitoring (Agumba \& Musonda 2014). Often, older and experienced students induce young students to indulge in negative tendencies in a 'follow suit' fashion that is less common among non-full-time students (Kyei \& Ramagoma 2013). This concurs with Agumba and Musonda's (2014) views that attribute the intensity of drug abuse to freedom and experimentation resulting from the need to test the limits previously set by parental and school monitoring.
In a university setting, it can be argued that academic expectations among students should be a deterrent to heavy substance abuse and associated problems (Levy \& Earleywine 2003). Nonetheless, some studies have noted that peer pressure is the most predictive variable among factors that influence substance abuse in universities (Kyei \& Ramagoma 2013). Thus, the potential for drug use to inhibit desirable academic performance and their subsequent career prospects upon completion of their studies is worrisome. Like alcohol, drugs such as marijuana and cocaine do have the same effect of disturbing the sleeping cycle and may impact on the level of alertness of the user for a couple of days. Furthermore, drug abuse suppresses neuronal activity in the hippocampus, resulting in problems with attention, memory and concentration (Schwartz 2001), conditions that are detrimental to the mental alertness required for academic pursuits. Recent studies in some African universities have also confirmed that drugs such as marijuana directly impair academic abilities, with negative results on performance. In addition, negative effects emanating from drug abuse, including stigmatisation of the users, fear of arrest, rejection from fellow students and loss of appetite, have been cited as factors that may lead to dropping out (Agumba \& Musonda 2014; Tuwei 2014).

\section{Institutional drug control efforts at the University of Limpopo}

Whereas substance abuse was uncommon and rarely reported about in the pre-1994 South African era, the post-apartheid media have somewhat highlighted the consequences of both alcohol and drug use among citizens, particularly through audio-visual reportage and press coverage (Mokwena 2016). In addition to government- and civic society-driven efforts, these efforts have increased the level of awareness about the effects of drug use and behaviour transformation, particularly among youth. In most South African universities, the drug control mechanism is largely informed by the Drugs and Trafficking Act (2014), which criminalises the selling and use of illicit drugs such as cocaine and heroin on their premises (University of Limpopo 2014b). Complimentary to the efforts of the South African Police Service (SAPS), campuses usually enforce these regulations through contracting safety and security services to privately owned companies responsible for law enforcement on campuses.

The University of Limpopo has responded to substance abuse through a multisectorial information-based approach aimed at holistically promoting, developing and creating a conducive learning environment for its students through provision of student-focused programmes. Essentially, these begin with the Orientation Week, which targets first entering students; the First Things First Campaign, which informs new students particularly about HIV/AIDS counselling and testing; Residence Life Talks, which promote adaptive skills for campus life, including prohibition of substance abuse; and the Annual Crime Awareness Campaign held in 
partnership with the SAPS later in the academic year (University of Limpopo 2014a; 2015). Nevertheless, one of the critically relevant sections of the university's contingent efforts that deals directly with the effects of substance abuse, albeit mostly in an individually based setting, is the Centre for Student Counselling and Development (CSCD).

The centre ensures the availability of campus counselling support services as a link between the individual student and the university community, which function under the guidelines provided by the centre. The centre boasts professional psychologists registered with the Health Professions Council of South Africa. A group of trained peer counsellors forms an extension of student counselling services in campus to complement the effort of professional staff (Mogane 2017). Their services range from dealing with depression, schizophrenia, post-traumatic stress disorder, stress and self-esteem improvement to anti-rape campaigns often provided through printed material in the form of small media such as pamphlets, brochures and leaflets. Nonetheless, most of these activities make a peripheral reference to drug abuse per se and therefore have no direct bearing on the abusers, particularly postgraduate students, who are conspicuously not directly linked to the programme.

\section{Population, sampling and sample size}

The study population consisted of users of a variety of drugs who resided at the postgraduate village on campus. Sampling entailed screening for inclusion, where participants' age and alertness to ascertain their level of soberness were observed to ensure that they understood the purpose of the study and that they could give consent to the interviewer. Two staff members were purposively selected on the basis of their expertise in student counselling and development, whereas both male and female drug users studying towards their master's qualification were the target population. This process yielded a total of nine $(n=9)$ participants consisting of two females and seven $(n=7)$ males selected using a non-probability snowball sampling technique, through which a known drug user helped to identify other users to form the sample. A former student peer educator was engaged to facilitate the recruitment and to arrange appointment times with potential participants within the selection criteria.

\section{Data collection and analysis}

In-depth interviews were conducted with participants at a convenient area arranged by the research assistant. Although interviews were conducted in the English language as participants felt comfortable to do so, some participants often code-switched to the local Sepedi, Xitsonga and Tshivenda languages. A recording device was used to assist with the storage and transcribing process of data into English. Interpretive phenomenological analysis was adopted for the development of themes, from which study findings and conclusions were drawn. This involved capturing, familiarisation and interpreting data in terms of the unique nature of the personal accounts on drug use as experienced by study informants.

\section{Ethical consideration}

Despite the predictably unrestrained behaviour of most drug users, the researcher ensured that all participants involved in the study were mentally vigilant to provide informed consent to participate in the study. Informants were also assured of the confidentiality of their contributions and anonymity of their personal details.

\section{Data presentation, results and discussion \\ Sociodemographics of student participants}

Table 1 presents the biographical data of the participants.

\section{Gender, level and mode of study}

The participants' demographic information yielded seven $(n=7)$ male and two $(n=2)$ female student drug users. Although the study used a convenience sampling technique, this proportional bias regarding the gender of participants confirms Ajao et al.'s (2014) finding that there is usually a higher percentage of drug use among males than females. All but one of the participants were in the second through fifth year of their MSc or MA studies in the university. This is despite the institution's stipulated 2-year turnaround period for full-time study and 3 years for part-time study for postgraduate students. This is an indication that suggests possible negative effects of drug use on the academic performance of drug users, as also noted by Orisatoki, Jayaraj and Oguntibeju (2008).

TABLE 1: Presentation of participants' demographic information.

\begin{tabular}{|c|c|c|c|c|c|c|c|c|c|}
\hline Participants' demographics & CD 1 & CD 2 & CD 3 & $\mathrm{CD} 4$ & CD 5 & CD 6 & CD 7 & $\mathrm{CD} 8$ & CD 9 \\
\hline Gender & M & $M$ & $\mathrm{~F}$ & $M$ & $M$ & $M$ & $M$ & $M$ & $\mathrm{~F}$ \\
\hline Age in years & 33 & 25 & 25 & 32 & 27 & 23 & 29 & 22 & 23 \\
\hline Year of study (MSc/MA) & 2 & 3 & 4 & 4 & 2 & 3 & 3 & 5 & 4 \\
\hline Full-time/part-time & $F / T$ & $\mathrm{~F} / \mathrm{T}$ & $\mathrm{F} / \mathrm{T}$ & $\mathrm{F} / \mathrm{T}$ & $\mathrm{F} / \mathrm{T}$ & $\mathrm{F} / \mathrm{T}$ & $\mathrm{F} / \mathrm{T}$ & $\mathrm{P} / \mathrm{T}$ & $F / T$ \\
\hline Employment status & $N / E$ & $N / E$ & $N / E$ & $N / E$ & $N / E$ & $N / E$ & $N / E$ & EMP & $N / E$ \\
\hline Age at first use of drugs & 18 & 15 & 19 & 17 & 14 & 20 & 18 & 19 & 18 \\
\hline History of drug use & 15 & 10 & 6 & 15 & 13 & 3 & 11 & 3 & 5 \\
\hline Counts to rehab centre & 0 & 0 & 0 & 0 & 0 & 0 & 0 & 0 & 0 \\
\hline Marital status & $M / D$ & $\mathrm{U} / \mathrm{M}$ & $\mathrm{U} / \mathrm{M}$ & $\mathrm{U} / \mathrm{M}$ & $\mathrm{U} / \mathrm{M}$ & $\mathrm{U} / \mathrm{M}$ & $\mathrm{U} / \mathrm{M}$ & $\mathrm{U} / \mathrm{M}$ & $\mathrm{U} / \mathrm{M}$ \\
\hline
\end{tabular}

CD 1-9, coded identities for participants; $M$, male; F, female; F/T, full-time; $P / T$, part-time; N/E, not employed; EMP, employed; $M / D$, married; $U / M$, unmarried. 


\section{Age, marital and employment status}

Despite the mean age of 27 years $(\mu=27)$, only one $(n=1)$ participant was married, whereas another one $(n=1)$ was employed on a part-time basis. In the backdrop of the participants' socio-economic backgrounds, only two $(n=2)$ of the participants were bursary holders whereas $(n=3)$ of them confirmed having lost their bursaries because of not completing within the prescribed time. This is worrisome considering that people of this age usually are expected to be financially independent to be able to look after themselves, including financing their personal endeavours such as further academic improvement.

\section{Age of onset and history of drug use}

The average age of onset was 17.5 years among all the participants but was higher among females (18.5 years) and lower among males (17 years), respectively. The average starting age of below 18 years concurs with Orisatoki et al.'s (2008) findings that, despite gender variations, often determined by class of drugs used, substance use can start at any age in life. One of the participants (CD 3) reported using drugs at the age of 18 years and traced this behaviour back to the time when he used to smoke cigarettes at the age of 14 years because of peer pressure. This implies that some of the drug users within the current postgraduate cohort started using substances at a young age. Usually, this behaviour becomes affirmed when these youngsters receive the 'initiation experience' (Agumba \& Musonda 2013) upon entering the university as a result of influence from senior students who use drugs. Study results also noted that the history of drug use among the participants was 9 years. The average period of 9 years of drug use among the participants indicates the addictive nature of drug use and the possible difficulty involved in quitting. This was confirmed by one of the expert interviewees (PP 2), who noted that even though most students on campus did not start early, those who had smoked for at least 5 years $(>5)$ often become addicted and therefore can hardly respond promptly to drug abuse treatment. Arguably, this situation may lead to untoward effects including failing to meet occupational obligations (Pham-Kanter 2006).

\section{Prevalence and type of commonly used drugs}

All male participants concurred on the existence of a 'community of smokers who use all sorts of drugs' among university students. This was confirmed by the two female participants (CD 4 and CD 9), who further remarked that drug use was a 'normal activity in campus' among both male and female students. As also noted by Ajao et al. (2014), the study noted a positive skewedness towards more males as regular drug users than females, who are occasional users, being active particularly on special days. Participants further revealed that drugs mostly used by postgraduate students were dagga or weed $(n=9)$, followed by hubbly-bubbly $(n=4)$, nyaope $(n=3)$ and to a lesser extent cocaine $(n=1)$. Dagga, also known as marijuana or cannabis, was reportedly the most popular drug because of both its affordability (about R30 a match box) and convenient 'underground drug network' supply chain, which was easily accessible at off-campus strategic points.
In agreement with the above scenario, one participant remarked, without disclosing the distribution area, that:

'... weed is as accessible as airtime around here.' (CD 1)

Despite the relatively low cost of about R25-R40 a joint (or drug portion), there were contextual factors to both the distribution and accessibility networks. A participant lamented how the cost of the 'stuff' contributed to economic want, resulting in:

'... need and poverty engulfing my family ... because no-one is employed at home'. (CD 9)

In relation to the cost, another participant said that:

'... the stuff is much (much) affordable in Jozi ... they get it cheap there, unlike here and this worsens our poverty because we depend on it for solace ... sometimes at the expense of food, you know!' (CD 6)

Surprisingly, one participant reported in a jovial mood that the supply dynamics were sustained by tactical recruitment of potential drug users among students from affluent families, who sponsored drug purchase for:

'... pleasure and love of creativity ... just like artists ... musicians and producers do.' (CD 2)

This concurs with both experts' views that the level of prevalence was partially influenced by the accessibility, affordability as well as the communitarian leverage resulting from aided supply mechanisms. According to the respondents, nyaope was relatively not prevalent because of the negative stigma associated with its chemical composition (usually mixed with painkillers, rat pellets, spirits, benzene, ARVs, etc.), whereas cocaine was prohibitively expensive for students to sustain its use. Despite all student participants being dagga smokers, they acknowledged nyaope as more addictive than other drugs, a factor also echoed by Health 24 (2014), which regards it as South Africa's worst drug.

\section{Awareness of psychosocial and health risks of drug use}

All participants $(n=9)$ admitted to being aware of the diverse psychosocial and health risks incurred not only by users but also by their respective families as well as the entire community within which drugs are used. Participants' awareness of users' experiences of illicit drug use, in particular, were similar in many respects, citing potential addiction as the major problem, subsequent physical discomfort after an irregular interval of not smoking and consistent relapse. Although nearly all $(n=8)$ participants acknowledged temporary therapeutic relief from pain resulting from frequent 'pulls' as an easier option to dealing with concomitant distress, they admitted knowing someone or a relative whose health condition had been ruined because of drug dependence.

Participants were clear about the effect of drugs and subsequent consequences, including how drug use changes users' mood and causes loss of concentration and focus in life. 
Their remarks made vivid inferences to users' eventual lack of emotional strength to successfully overcome the addictive nature of drug use. These experiences concur with Moore, Guarino and Marsch's (2014) study of opioid-dependent youth, who acknowledged the ruinous and distasteful experiences of drug abuse. The study described this experience in terms of the gradual complications that follow the initial desirable feeling and the resultant cravings that evolve with intensity of drug dependence. While psychological models on how to deal with drug abuse suggest motivational strength or determination by the addicts to quit drug abuse (Mokwena 2016), five $(n=5)$ of the participants (CD 1, CD 5, CD 6, CD 7 and CD 9) said this tendency often leads to more cravings, which subsequently invokes a stronger indulgence or desire to get more successive pulls. Hence, frequent use often results in economic consequences, where the cost of drugs end up directly competing with or impeding on the purchase of basic needs such as food and clothing.

Data about health risks associated with drug use by most of the participants $(n=7)$ indicated that some drugs, including marijuana, can enhance users' creativity and social mood, sharpen one's intelligence, prompt the level of focus and boost sexuality. This is analysed within the backdrop of one female participant's claims regarding marijuana's cosmetic attributes and value as being:

'... very good for skin and treatment of dehydration ... as well as managing weight loss.' (CD 4)

However, both expert interviewees (PP 1 and PP 2) remarked that often drug users, particularly nyaope smokers, complain of feeling sickly or sleepy, portray half-dazed looks and lack good personal hygiene. These symptoms were also noted by Mokwena (2016) in her study of students' use of nyaope at the Medunsa Campus, now Sefako Makgatho Health Sciences University. In addition, two participants with the longest history of drug use (CD 1 and CD 4) admitted to developing 'darkened lips and stained teeth' because of prolonged use of drugs. Among the rest of the participants, there was general acknowledgement that drug use (particularly of an illicit nature) could lead to acute health effects such as weight loss and stomach cramps because of drug dependence.

\section{Knowledge and use of existing drug management services}

Participants reported no knowledge of any other rehabilitation centre on campus save for the CSCD and the accompanying activities of peer counsellors, whom they perceived to be assigned to undergraduate students only. Two participants (CD 3 and CD 9) cited Mankweng Hospital (outside the campus) as the referral centre but denied that drug users at their level 'would ever need help from social workers or clinical psychiatrists or psychologists' because they (drug users) had no problem. This was echoed by another participant, who exclaimed that:

\footnotetext{
'... drugs do not control your mind ... you do things consciously ... because weed for example is not a drug, the experience is irreplaceable.' (CD 2)
}

One participant also retorted:

'What for ...? Psychoactive stuff generates confidence and enhances what already exists (in you). When you're high, you calm down and forget stuff and be in the imaginary world, neh ... ! No violence, isn't it that you control the activity ... you are well.' (CD 4)

The above sentiments were confirmed by both expert interviewees (PP 1 and PP 2), who noted that drug users often 'feel like superheroes or celebrities', who tend to display fearless and carefree attitudes towards other people including counselling personnel. In addition, three $(n=3)$ other participants viewed rehabilitation as a lengthy process that seems to be inconsiderate of the immediate negative experiences associated with withdrawal effects of drug use. While existing drug control systems such as the Safety and Security Unit as well as the CSCD mainly focus on individual student misdemeanours including deterring drug trading and abuse, both expert informants (PP 1 and PP 2) noted that systematic outreach campaigns targeted at larger groups of students, particularly postgraduates, were less evident. To a large extent, this confirms some of the participants' view that the existing drug management services on campus focus mainly on undergraduate students rather than postgraduates.

\section{Behavioural impediments to students' career prospects}

This section addresses behavioural impediments that have the potential to obstruct possible employment prospects among postgraduate students who use drugs. Although participants raised numerous disorders that can inhibit one's career prospects, this analysis focuses mainly on denial and lack of coping strategies, improper personal conduct, unresponsive behaviour, poor academic performance, and incriminated personal profile.

\section{Denial and lack of coping strategies}

Because of the numerous social problems encountered by students, there was a strong need for them to be:

'... calmed down, escape this body just like someone in a plane ... and be carefree'. (CD 4)

Notably, most of the participants $(n=7)$ retorted that drug users who report negative outcomes of drug use such as:

'losing control of themselves ...' [particularly after smoking dagga or weed, were] novices ... who become hyperactive and careless' (CD 1).

Two participants (CD 3 and CD 8) argued that although there are different types of dagga, 'the well-prepared one, especially from Swaziland, brings pleasure, invigorates ... and relieves stress'. Other phrases used by participants (CD 7, CD 4 and CD 9) to describe the affective experiences of smoking other forms of drugs or cocktail (including illicit substances) comprised 'building confidence', 'calming down', 'stress relieving', 'stimulates creativity', 'rekindles dormant ideas' and 'sharpening one's creativity'. These remarks are vivid denial antics showing that participants did not see drug use 
as a problem but rather viewed it as a recreational experience. Such were sentiments made by one participant who remarked that:

'No! This is not an intoxicant ... it is a recreational drug ... because it creates socialites.' (CD 9)

This scenario fits within the comments of one expert, who maintained that drug use among postgraduate students was used as part of:

'Coping strategy to boredom or idleness resulting from the students' failure to use the ample time they have ... since most of them are not attending class ... but doing research only. This is further made worse by unemployment and anxiety of ... what about if things go wrong or go on like this? ... or other forms of frustrations.' (PP 1)

Essentially, the preceding refers to the transitional and adaptive challenges evolving from poor handling of a crammed module-based curricula to a self-driven researchedbased mode of learning, which most postgraduate students fail to adjust to. In the second expert's view:

'Coursework, tests and examinations do not allow students to go for a pull ... so when you eat kush (whoonga), you become hungry and this disturbs reading or writing.' (PP 2)

Subsequently, the expert said this develops to an behaviour that tends to negatively affect drug users who cannot multitask, leading to late submission of academic work or total non-submission, such as:

'... ever-partying mood or bashing.' (PP 2)

Therefore, denial makes it difficult for drug users to receive treatment, while lack of coping strategies increases drug dependence.

\section{Improper personal conduct and unresponsive behaviour}

This aspect looks at personal conduct and trainability as the defining features of a potential employee who can meaningfully contribute to the productivity of any sector in the market. Both expert interviewees (PP 1 and PP 2) highlighted that some drug users, particularly males, have a tendency of displaying outright arrogance, poor personal hygiene, negligence, disrespect and potential violent behaviour because of drug abuse. Two $(n=2)$ participants acknowledged being distressed after observing that when they were amateur drug users at the undergraduate level a few years ago, their social condition had:

'... turned into bad taste.' (CD 9)

With the benefit of hindsight, they categorically stated that users usually become:

'... less hygienic, careless and become reckless with their finances.' (CD 9)

Another participant (CD 4) said she once dropped out and took a break from her studies because of inability to focus on her academic work. This concurs with study findings by Ajao et al. (2014) and Mokwena (2016), who noted low concentration, lack of interest, slow progress and strained relationships with inmates in the residences as offshoots of substance abuse. In view of this context, drug use could account for the manner in which potential employees would manage issues around punctuality to the workplace, emotional balance or stress management, teamwork and the ability to meet deadlines.

\section{Academically unimpressive and incriminating personal profile}

A majority of the participants $(n=8)$ said drug use had no effect whatsoever on their academic work but rather claimed that it invigorates them and helps them to stay focused and 'smart'. One participant (CD 2) alluded to the level of exposure and experience that postgraduate students have in dealing with academic tasks, while another (CD 5) claimed that this was owed to study progress that can be easily managed over time. However, expert knowledge from both interviewees (PP 1 and PP 2) as well as literature on the effects of drug use on academic performance show that low concentration, irregular class attendance, missing assignment deadlines and poor examination scores are consequent outcomes of drug abuse (Orisatoki et al. 2008). In addition, the section on participants' demographic profiles noted three $(n=3)$ students who reported being in their fourth year while one $(n=1)$ was in the fifth year of study towards a masters' degree qualification. This may be an indication of students' failure to use their academic time productively, a tendency that affected the turnaround period to complete their studies. Notably, all participants acknowledged that most potential employers, including the government, prefer to recruit people with the best results and that an extended stay or delayed completion of one's studies (usually reflected in the academic transcript) dissuades them from shortlisting weak candidates.

The consequences of poor academic performance are further complicated by evidence of one having an incriminating record against one's name, particularly if one has been found guilty of breaking the laws that regulate drug use. Despite this, there are also some stereotypical perceptions, which one of the participants confirmed by saying that:

'drug users are usually seen as untrustworthy ... to most emplyees.' (CD 2)

In spite of this not being a crime, it minimises the drug users' prospects for employability and resonates with the study findings, where some sober (not high) participants were noticed displaying drug user persona features such as being restless, hanging their fingers in the air and winking their eyes at the interviewer during the interview. One expert interviewee (PP 1) noted that professions such as teaching, social work, legal practice, the SAPS and various categories within the medical profession impeccably monitor unprofessional conduct, with substance abuse not being an exception. For this reason, persons who have been involved in any form of criminal activity, including possession of illicit 
drugs or other petty crimes, spontaneously limit their career opportunities in their respective trades. In addition, some employers do require urine tests for presence of drugs before concluding contractual agreements. Although this does not mean that the user has a criminal record, it however implies partaking in illicit activities such as buying drugs. Thus, in addition to a weak academic record and any form of criminal record, these issues are unfavourable elements that can inhibit a postgraduate's career prospects.

\section{Implications for career counselling intervention strategies}

The study noted that denial and a lack of coping strategies; an improper personal conduct and an unresponsive behaviour; a poor academic performance and an incriminated personal profile were the major potential impediments that could inhibit students' career prospects. A combination of these factors creates an occupational ambience of barriers that can hardly be addressed through fear or scare tactics and information-based programmes often adopted by universities. While existing intervention programmes play a crucial role in creating awareness about substance abuse, their success rate and effectiveness in controlling drug use on campus are usually weakened by lack of regular review or not being subject to systematic evaluation. As one expert participant summed up:

'Despite their minimal nature, existing intervention campaigns were not specifically dedicated to addressing challenges on drug abuse and control systems.' (PP 1)

Instead, they broadly assumed a generic approach to students' collective psychosocial issues affecting their university life. Notably, some of the participants (CD 1, CD 4 and $C D$ 7) confirmed that these activities hardly attracted postgraduate students, most of whom believed that they had outgrown the scope of these interventions and therefore felt logically disengaged and were not bothered to participate. Overall, this calls for more inclusive strategies on the development of social skills to address poor social coping strategies, mundane decision-making, low self-esteem and weak peer pressure resistance mechanisms.

Furthermore, the preceding limitations call for more creative ideal career counselling intervention programmes that are compatible with the local sociocultural contexts that include poverty ramifications. Because of the large number of drug users, coupled with their unprivileged socio-economic status and shortage of rehabilitation centres, the institution needs to use a group approach rather than an individual focus to deal with the prevalence of drug use among all the students (Tayob \& Van der Heever 2014). Thus, cost-free drug and alcohol abuse colloquia should be provided to help minimise drinking, smoking and administering hard drugs among postgraduate students. This should be in tandem with the thrust towards strengthening referral links between the university and community referral centres to augment efforts from the university. The effectiveness of this approach will also be determined by the collaborative nature of the interventions, which according to this study should involve specific departments and academic staff of the university where the students are registered. This could be done in the form of career development seminars that can help students to self-introspect and possibly develop a self-assessment mechanism to determine their state of drug indulgence, meanwhile monitoring their quitting behavioural patterns.

\section{Conclusion}

Owing to its multidimensional nature, the challenge pertaining to the use of psychoactive substances among postgraduate students, particularly drugs, needs to be prioritised in order to promote effective and sustainable intervention programmes in universities. Noting that the experiences of drug users often degenerate to potential addiction levels in the short-medium term (Masombuka 2013), this calls for urgent attention for the design and implementation of career-oriented counselling strategies from which postgraduate students could develop professionally. Essentially, this should entail a review of the existing drug and alcohol use control mechanism to include career-enhancing training such as entrepreneurial skills, time management, creating job-hunting networks and interview skills. This could subsequently be augmented by colloquia located within the life skills approach to address a range of psychosocial challenges such as denial and lack of coping strategies, mundane decision-making and peer pressure resistance, meanwhile inculcating responsible personal behaviour that promotes career enhancement.

\section{Acknowledgements}

The authors thank the University of Limpopo's Centre for Student Counselling and Development and Postgraduate Student Association for their assistance during data collection for the article.

\section{Competing interests}

The authors declare that they have no financial or personal relationships which may have inappropriately influenced them in writing this article.

\section{Authors' contributions}

T.M. was responsible for the initial stages of the development of the research. This involved the preliminary observations from which the rationale of the study was derived, formulating the research problem and the objectives. T.M. did the initial literature review and designed the interview schedule and collected data through interviews with participants. C.J.R. assisted by expanding the literature for the article, developing themes from the data as well as the interpretation and formulating of the findings were done in conjunction with T.M. C.J.R was aslo responsible for the methodological presentation of the article and its technical construction were part of the contribution. The overall integration of the various components of the research was ensured through academic writing and logical flow of the article - there were were essential contributions to the academic soundness of the article. 


\section{References}

Agumba, N. \& Musonda, I., 2014, 'Perception of the effects of substance abuse among university students: A case of Built Environment and Civil Engineering students at a South African university in Gauteng Province', in Proceedings of the 3rd International Conference on Economics and Social Sciences (ICESS-2014), Johannesburg, July 03-06, 2014, pp. 269-276.

Ajao, B., Anyanwu, F.C., Akinsola, H.A. \& Tshitangano, T.G., 2014, 'Knowledge, attitudes and practices of substance abuse among university students', African Journal for Physical, Health Education, Recreation and Dance 20(1), 214-224.

Goreishi, A. \& Shajari, Z., 2013, 'Substance abuse among students of Zanjan's universities (Iran): A knot of today's society', Addiction \& Health 5(1-2), 66-72.

Health 24, 2014, Is Nyaope South Africa's worst drug?, viewed 09 June 2016, from http://www.health24.com/ILifestyle/Street-drugs/News/street-drug-nyaopeclassified-as-illegal-20140403

Kyei, K.A. \& Ramagoma, M., 2013, 'Alcohol consumption in South African Universities: Prevalence and factors at the University of Venda, Limpopo Province', Journal of Social Sciences 36(1), 77-86. https://doi.org/10.1080/0971 8923.2013.11893175

Levy, B. \& Earleywine, M., 2003, 'Reinforcement expectancies for studying predict drinking problems among college students', Addictive Behaviors, viewed 29 October 2018, from http://search.ebscohost.com/login.aspx?direct=true\&db=ed sbl\&AN=RN127853617\&site=eds-live

Masombuka, J., 2013, 'Children's addiction to drug "Nyaope" in Soshanguve Township: Parents' experiences and support needs', Master's dissertation submitted to the University of South Africa.

Matlou, M.L., 2016, 'Binge drinking, crime and victimisation during bashes at the University of Limpopo', Unpublished MA dissertation, University of Limpopo, Sovenga.

Mogane, M., 2017, Centre for Student Counselling and Development (CSCD). 2017 orientation, Prosper, UL Printing, Sovenga.
Mokwena, K., 2016, "'Consider our plight": A cry for help from Nyaope users', Health SA GESONDHELD 21(2916), 137-142. https://doi.org/10.4102/hsag.v21i0.944

Moore, S.K., Guarino, H. \& Marsch, L.A., 2014, "This is not who I want to be": Experiences of opiod-dependent youth before and during, combined Buprernophine and behavioural treatment', Substance Use and Misuse 49(3), 303. https://doi.org/10.3109/10826084.2013.832328

Orisatoki, R.O., Jayaraj, A.D. \& Oguntibeju, O.O., 2008, 'Substance abuse among students at a Caribbean university', Medical Technology SA 22(1), 9-12.

Peltzer, K. \& Ramlagan, S., 2009, 'Alcohol use trends in South Africa', Journal of Social Sciences 18(1), 1-12. https://doi.org/10.1080/09718923.2009.11892661

Pham-Kanter, G., 2006, 'Substance abuse and dependence', in J.L. Lounge (ed.), Gale encyclopaedia of medicine, 3rd edn., Thomas Gale, Farmington, pp. 59-77.

Schwartz, G., 2001, 'How do drugs and alcohol impede students' academic progress?', Recruitment and Retention in Higher Education 15(11), 87-101.

Tayob, S.M. \& Van der Heever, H., 2014, 'Alcohol use among the students at the University of Limpopo', African Journal for Physical, Health Education, Recreation University of Limpopo', Africc
and Dance 1(2), 364-373.

Towl, D., 2004, Alcohol use and tertiary students in Aotearoa-New Zealand, ALAC Occasional Publications University of Otago, Wellington, No. 21, pp. 1-40.

Tuwei, P.C., 2014, 'Influence of drug use on students' academic performance in public universities: A case Ausin Gishu county in Kenya', A Master of Arts dissertation submitted to the University of Nairobi, Kenya.

United Nations, 2014, World Drug Report, United Nations Office on Drugs and Crime (UNODC), New York, NY.

University of Limpopo, 2014a, University of Limpopo annual report, UL Printing, Sovenga. Marketing and Communication, UL Publications.

University of Limpopo, 2014b, University of Limpopo student service guide, 2014, UL Printing, Sovenga. Marketing and Communication, UL Publications.

University of Limpopo, 2015, University of Limpopo annual report, UL Printing, Sovenga. Marketing and Communication, UL Publications. 